\title{
An Optical Fiber Sensor Based on Fluorescence Lifetime for the Determination of Sulfate Ions
}

\author{
Liyun Ding ${ }^{1, * \mathbb{D}}$, Panfeng Gong ${ }^{1}$, Bing $X \mathbf{u}^{1}$ and Qingjun Ding ${ }^{2}$ \\ 1 National Engineering Laboratory for Fiber Optic Sensing Technology, Wuhan University of Technology, \\ Wuhan 430070, China; 278242@whut.edu.cn (P.G.); xb2016@whut.edu.cn (B.X.) \\ 2 School of Materials, Science and Engineering, Wuhan University of Technology, Wuhan 430070, China; \\ dingqj@whut.edu.cn \\ * Correspondence: dlyw@whut.edu.cn; Tel.: +86-181-6400-2219
}

Citation: Ding, L.; Gong, P.; Xu, B.; Ding, Q. An Optical Fiber Sensor Based on Fluorescence Lifetime for the Determination of Sulfate Ions. Sensors 2021, 21, 954. https:// doi.org/10.3390/s21030954

Academic Editor: Richard

B. Thompson

Received: 9 December 2020

Accepted: 27 January 2021

Published: 1 February 2021

Publisher's Note: MDPI stays neutral with regard to jurisdictional claims in published maps and institutional affiliations.

Copyright: (c) 2021 by the authors. Licensee MDPI, Basel, Switzerland. This article is an open access article distributed under the terms and conditions of the Creative Commons Attribution (CC BY) license (https:// creativecommons.org/licenses/by/ $4.0 /)$.

\begin{abstract}
A new optical fiber sensor based on the fluorescence lifetime was prepared for specific detection of sulfate ion concentration, where 1,1'-(anthracene-9,10-diylbis(methylene))bis(3(dodecylcarbamoyl)pyridin-1-ium) acted as the sulfate fluorescent probe. The probe was immobilized in a porous cellulose acetate membrane to form the sensitive membrane by the immersion precipitation method, and polyethylene glycol 400 acted as a porogen. The sensing principle was proven, as a sulfate ion could form a complex with the probe through a hydrogen bond, which led to structural changes and fluorescence for the probe. The signals of the fluorescence lifetime data were collected by the lock-in amplifier and converted into the phase delay to realize the detection of sulfate ions. Based on the phase-modulated fluorometry, the relationship between the phase delay of the probe and the sulfate ion concentration was described in the range from 2 to $10 \mathrm{mM}$. The specificity and response time of this optical fiber sensor were also researched.
\end{abstract}

Keywords: optical fiber sensor; sulfate optical detection; fluorescence enhancement; phase-modulation fluorometry

\section{Introduction}

Sulfate concentration as an evaluation index of crystalline corrosivity has been the focus of research in the field of concrete erosion [1]. There are many reasons for the sulfate ion concentration in water to increase, such as the dissolution of gypsum and other sulfate deposits, sulfite and thiosulfate oxidation in the air, and the discharge of domestic sewage and industrial wastewater. Sulfate ions can react with cement hydration products to precipitate into expansive crystals, which bring about expansion, cracking, and strength loss in concrete structures [2-4]. The construction life of concrete structures will be seriously affected, and there is a hidden danger of causing major accidents [5-7]. Therefore, the monitoring of sulfate ion concentration in a concrete environment has important engineering and economic significance for the early warning of durability problems of concrete structures.

As an ion probe, special modified gold nanoparticles can be used to detect sulfate ions specifically. They can detect the different concentrations of sulfate ions through the aggregation degree of gold nanoparticles [8] and the fluorescence intensity of a complex [9]. Raman spectroscopy has also been reported for the determination of sulfate ions dissolved in pore water of sediments [10], and it realized the diurnal variability change monitoring of the $\mathrm{SO}_{4}{ }^{2-}$ intensity of offshore seawater [11]. Other techniques have been adopted to determine sulfate concentration, such as titration [12,13], atomic absorption spectroscopy (AAS) [14,15], ion chromatography (IC) [16,17], spectrophotometry [18], atomic fluorescence spectroscopy (AFS) [19], and inductively coupled plasma atomic emission spectroscopy (ICP-AES) [20,21]. Optical fiber sensors have many advantages compared with 
those detection methods: energy savings, high sensitivity, strong resistance to electromagnetic interference, enabling continuous remote monitoring, compactness, flexible shape, and real-time detection capability [22-25]. Combining sensitive material with a fiber optic sensor is a significant research direction which could prepare a sulfate fiber sensor, which has great potential for practical detection.

For ion detection, most of the receptors belong to the off type (fluorescence quenching), which means that the fluorescence emission intensity decreases when the analyte is combined. Although the off type of detection is widely used, fluorescence enhancement (on) is preferable to quenching (off) because it reduces the chance of false positives, is more suitable for multiplexing, and could use multiple detectors simultaneously to produce unique responses to different analytes [26,27]. A substance that can specifically bind sulfate ions and produce a fluorescent reaction is a superior fluorescent probe whose name is $1,1^{\prime}$-(anthracene-9,10-diylbis(methylene))bis(3-(dodecylcarbamoyl)pyridin-1-ium) (AMDP) [28]. The probe AMDP can combine with sulfate ions through hydrogen bonds to form a fluorescent complex and realize the detection of sulfate ion concentration based on the fluorescence enhancement effect. According to the molecular orbital theory [29], the reduced fluorescence effect of anthracene moiety in the probe AMDP is due to electron transfer between the anthracene moiety and the pyridine ring, which means that the photo-induced electron transfer (PET) effect is generated and prevents the generation of fluorescence. The sulfate group can bind to the two pyridine rings on the probe AMDP through hydrogen bonding, which invalidates the PET effect in the complex and restores fluorescence [30,31].

Fluorescence lifetime refers to the average residence time of molecules in the excited state before returning to the ground state after being excited by light pulse. The fluorescence lifetime is generally absolute and only related to the microenvironment of the fluorophore. It has been reported that fiber-optic sensors exist based on fluorescence lifetime to detect temperature [32], strain [33], and $\mathrm{Fe}^{3+}$ ion concentration [34] in solution. As it effectively avoids the inherent characteristics of fluorophore photobleaching, spectral drift, and inappropriate excitation light, the optical fiber sensor based on fluorescence lifetime detection has high-precision and stable detection performance.

In this paper, a novel method based on fluorescence lifetime for detecting sulfate ions was proposed by combining a sulfate-sensitive fluorescent cellulose acetate (CA) membrane with an optical fiber sensor. To immobilize the probe AMDP, the immersion precipitation method was adopted to prepare the sulfate-sensitive CA membrane. Polyethylene glycol (PEG) 400 was used as porogen to improve the porosity of the sensitive membrane and enhance the detection ability. The lock-in amplifier was used in the optical fiber sensor to collect and convert the fluorescence lifetime signal into a phase delay, which avoids the photobleaching effect to improve the anti-interference and detection capability of the sensor. Based on the principle of the phase-modulation fluorometry, the relationship between phase delay and sulfate ion concentration was researched. The sensing characteristics of the optical fiber sensor were further studied, including detection range, sensitivity, repeatability, and selectivity.

\section{Experimental Methods}

\subsection{Materials and Apparatus}

All chemicals used were of analytical-reagent grade. Cellulose acetate, dimethyl sulfoxide (DMSO), polyethylene glycol 400, sodium phosphate dibasic, sodium bromide, sodium iodide, sodium chloride, sodium carbonate, sodium persulfate, sodium thiosulfate, anhydrous sodium sulfate, sodium nitrate, magnesium chloride hexahydrate, calcium chloride, and sodium hydroxide were obtained from Sinopharm Chemical Reagent Co., Ltd (Wuhan, China). 1,1'-(anthracene-9,10-diylbis(methylene))bis(3-(dodecylcarbamoyl)pyridin-1-ium) was procured from Heowns Biochem Technologies LLC (Tianjin, China).

The Fourier-transform infrared spectroscopy (FT-IR) spectrum of the fluorescent complex was obtained by a Nexus (Nexus-470, Thermo Nicolet, Thermo Fisher Scientific, 
Waltham, MA, USA) intelligent Fourier transform infrared spectrometer. The scanning electron microscope (SEM) photograph of the sensitive membrane was obtained using a scanning electron microscope (JSM-7500F, Jeol, Japan). A lock-in amplifier (SR-830, Stanford Research Systems, Sunnyvale, CA, USA) was used to convert the fluorescent signal into phase shift information. Ultraviolet-visible (UV-Vis) adsorption spectrum and fluorescence spectrum were obtained from a UV-Vis spectrometer (UV-2450, Shimadzu, Japan) and fluorescence spectrophotometer (F-4500, Hitachi, Japan), respectively.

\subsection{Fluorescence Probe Detection of AMDP}

First, $0.1 \mathrm{mM}$ of standard fluorescent indicator solution was prepared by dissolving $1.07 \mathrm{mg}$ fluorescent probe AMDP in $10 \mathrm{~mL}$ DMSO. Then, $0.1 \mathrm{~mL}$ of indicator solution was added into $3 \mathrm{~mL}$ of $1 \mathrm{mM}$ sodium sulfate DMSO- $\mathrm{H}_{2} \mathrm{O}$ (3:7) mixed solution to detect the properties of the fluorescent complex. The optimal excitation wavelength and emission wavelength of the fluorescent complex were found by fluorescence spectra, and further discussed according to the UV-Vis adsorption spectra. The detection ability of AMDP for sulfate ion in different $\mathrm{pH}$ values was also studied. In addition, the luminescence time, fluorescence lifetime, complexation ratio, and photobleaching effect of the fluorescent complex were also investigated.

\subsection{Preparation of Sensitive Membrane}

Cellulose acetate sensitive membrane was prepared by immersion precipitation method [35-37]. DMSO was used as a solvent; $14 \mathrm{wt} \%$ cellulose acetate and $10 \mathrm{wt} \%$ PEG 400 were added to DMSO and stirred at room temperature for $6 \mathrm{~h}$ to dissolve. Then, $1.0 \times 10^{-4} \mathrm{M}$ fluorescent probe AMDP was added and stirred for $2 \mathrm{~h}$ to dissolve. Ultrapure water was used as a gel bath. The $3 \mathrm{~mL}$ casting solution was tiled in a petri dish with a diameter of $60 \mathrm{~mm}$, and then immersed in gel bath to form a membrane. After $2 \mathrm{~h}$ of membrane formation, the membrane was taken out from ultrapure water and dried at $30{ }^{\circ} \mathrm{C}$ temperature. Then, the sensitive membrane was characterized by scanning electron microscope and infrared spectrometer. Leakage experiment was conducted to verify the reliability of the sensitive membrane. The sensitive membrane was immersed in $10 \mathrm{mM}$ sulfate ion solution to restore fluorescence and keep for $96 \mathrm{~h}$. During this period, the absorption spectra of the solution into which the sensitive membrane was immersed were studied.

\subsection{Sulfate Ion Detection with the Optical Fiber Sensor}

The optical fiber sensor monitored the sulfate ion concentration by detecting the change of fluorescence lifetime, which avoided photobleaching and undesirable lightsource interference, thereby improving the reliability and accuracy of detection. The lock-in amplifier was adopted to collect fluorescence phase change data, and the schematic illustration of the optical experimental platform is shown in Figure 1. The bifurcated fiber bundle consisted of 37 identical plastic optical fibers, with a core diameter of $0.25 \mathrm{~mm}$ and a fiber cladding of $30 \mu \mathrm{m}$. The sensitive membrane was excited by an LED light source with emission wavelength of $410 \mathrm{~nm}$ at $40 \mathrm{kHz}$ frequency through the bifurcated fiber. The fluorescence signal was collected by an optical fiber contact (FC) optical connector, modulated by the lock-in amplifier, and then transmitted to the computer for further processing and recording. The sensitive membrane was cut into a small wafer of appropriate size and placed in the metal probe for detection. After each concentration of $\mathrm{SO}_{4}{ }^{2-}$ ions, the membrane needed to be replaced with a new one in the sensor. The sensitive membrane was fastened in the sensor probe through a metal fixing nut, and the diagram is shown in Figure 1. 


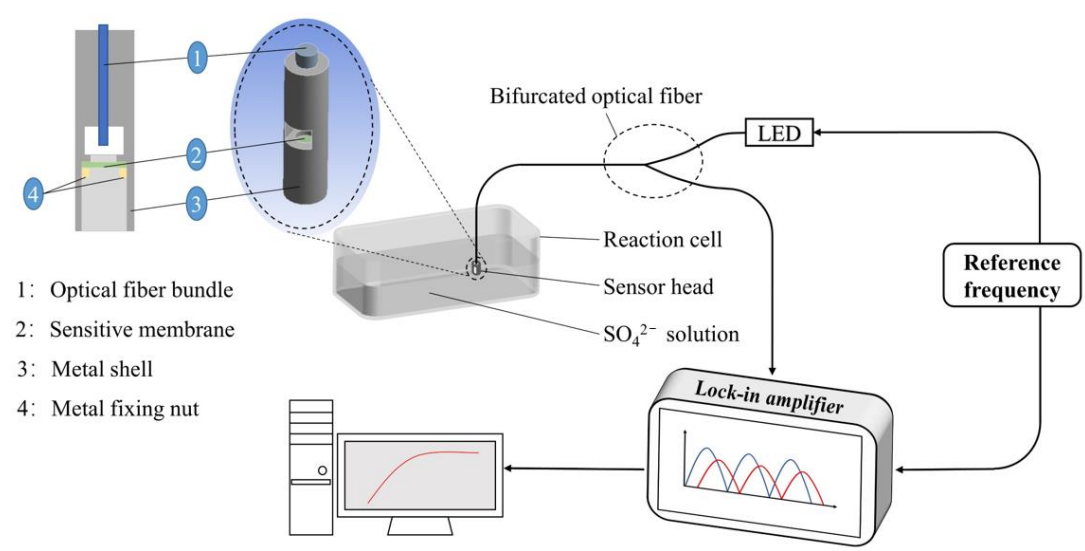

Figure 1. Schematic diagram of the optical fiber sensor.

The sensitive membrane was immersed in the solutions of the different sulfate ion concentrations, and $\mathrm{SO}_{4}{ }^{2-}$ combined with the fluorescent probe AMDP on the membrane to form a fluorescent complex to emit fluorescence. The relationship between fluorescence intensity, fluorescence lifetime, and concentration of $\mathrm{SO}_{4}{ }^{2-}$ could be described by Equation (1) [34]:

$$
\frac{I_{1}}{I_{2}}=\frac{\tau_{1}}{\tau_{2}}
$$

where $I$ is the fluorescence intensity and $\tau$ is the fluorescence lifetime of the sensitive membrane. In the formula, subscripts 1 and 2 mean data of the sensitive CA membrane with the different $\mathrm{SO}_{4}{ }^{2-}$ ion concentrations.

The fluorescence was emitted by the sensitive membrane via a $410 \mathrm{~nm}$ wavelength LED light source at $40 \mathrm{kHz}$ frequency $(f)$, which could be converted into phase shift information $(\varphi)$ by lock-in amplifier. The following equation shows the relationship between phase delay $(\Delta \varphi)$ and fluorescence lifetime [38,39]:

$$
\tan \Delta \varphi=2 \pi f \tau,
$$

the following equation can be obtained by combining Equations (1) and (2):

$$
\frac{\tan \Delta \varphi_{1}}{\tan \Delta \varphi_{2}}=\frac{\tau_{1}}{\tau_{2}}
$$

According to Equation (3), we can determine the change of fluorescence lifetime by the change of phase delay.

The prepared sensitive membrane was cut into prototype sheets of uniform size for the detection process. The assembled optical probe was immersed in the DMSO- $\mathrm{H}_{2} \mathrm{O}$ (3:7) solution to detect its sulfate concentration to obtain the standard concentration curve and formula. According to the environmental requirements of real detection [4], the concentrations of sulfate in the solution were $0,2,4,6,8$, and $10 \mathrm{mM}$.

There are many other anions in the concrete environment, so to detect the specificity of the optical fiber sensor, the experiment proceeded with the anions of $\mathrm{HPO}_{4}{ }^{2-}, \mathrm{Br}^{-}, \mathrm{Cl}^{-}$, $\mathrm{CO}_{3}{ }^{2-}, \mathrm{I}^{-}, \mathrm{S}_{2} \mathrm{O}_{3}{ }^{2-}, \mathrm{SO}_{3}{ }^{2-}$, and $\mathrm{NO}_{3}{ }^{-}$under the same conditions as sulfate.

\section{Results and Discussion}

\subsection{Characterization of the CA Membrane}

SEM images were taken in order to explain the effect of PEG 400 on the morphology of the sensitive CA membrane. Figure 2a depicts SEM surface section image of sensitive membrane produced without PEG, and the surface micromorphology shows many microsized holes and pits. These holes and pits of the surface are not connected with the interior, as shown in the cross-section of Figure 2b. As the solvent of casting solution, DMSO was 
gradually replaced by ultrapure water when the casting solution was immersed in a gel bath, which led to cellulose acetate gradually precipitating on the membrane. At the same time, PEG 400 rapidly moved from the casting solution to the ultrapure water because of its good compatibility with ultrapure water, resulting in many pore channels left in the membrane. The addition of the porogen, PEG 400, obviously promoted the formation of pores on the surface of the membrane and made a three-dimensional pore structure form in the membrane, as shown in Figure 2c,d. When the sensor with a porous, sensitive CA membrane was used to detect sulfate solutions, the surface and internal pores of the membrane allowed the sulfate ions in solution to fully contact AMDP, which promoted the enhancement of the fluorescence of the sensitive membrane and thus the detection of the sensor. As shown in Figure 2c, the SEM image was processed, and the results showed that the average pore size of CA membrane was $0.574 \mu \mathrm{m}$.

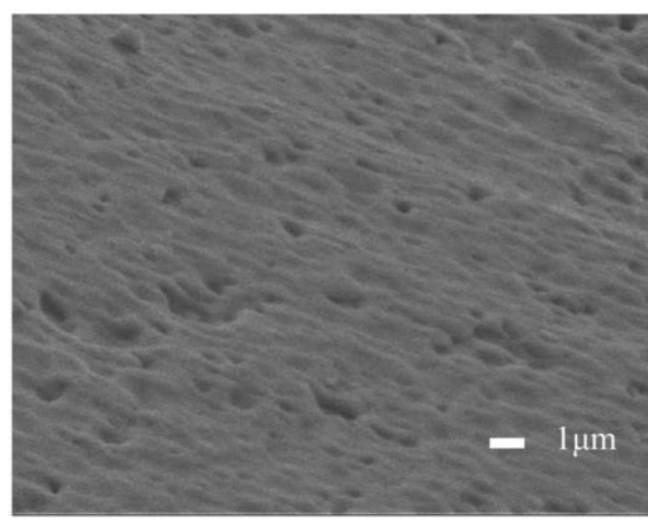

(a)

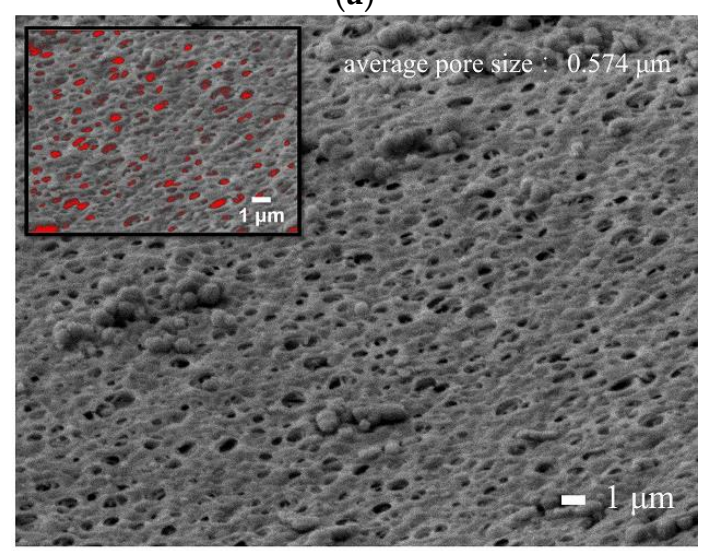

(c)

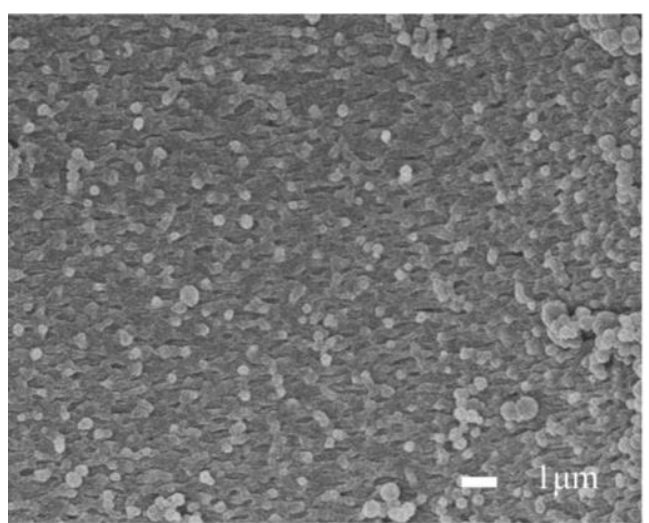

(b)

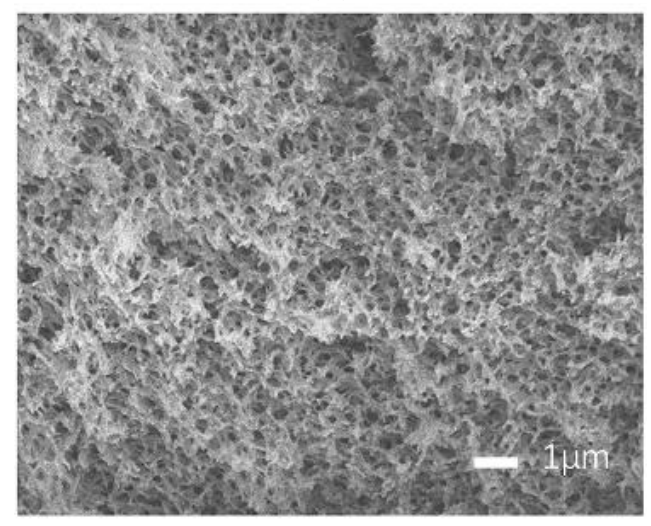

(d)

Figure 2. SEM images of sensitive CA membrane. Surface section (a) and cross-section (b) of the membrane without PEG 400; surface section (c) and cross-section (d) of the membrane with PEG 400.

The chemical structure of the fluorescent probe AMDP is shown in Figure 3a [28] and the FT-IR spectra of the CA membrane with and without the addition of AMDP are shown in Figure $3 b$. The CA membrane with AMDP has a series of characteristic peaks by comparison, such as $3089,2928,2856,1664,1589,1501 \mathrm{~cm}^{-1}$. The absorption peak at $3089 \mathrm{~cm}^{-1}$ is the $\mathrm{C}-\mathrm{H}$ stretching vibration peak of the aromatic hydrocarbon ring; the peaks at 1589 and $1501 \mathrm{~cm}^{-1}$ are both stretching vibration peaks of the aromatic hydrocarbon ring skeleton; the peaks at 2928 and $2856 \mathrm{~cm}^{-1}$ are respectively the $\mathrm{C}-\mathrm{H}$ antisymmetrical and symmetrical stretching [40] vibration peaks of the alkane; the peak at $1664 \mathrm{~cm}^{-1}$ is the $\mathrm{C}=\mathrm{O}$ stretching vibration peak of the amide [41]. Within the fingerprint region, the absorption peaks 845 and $675 \mathrm{~cm}^{-1}$ are the out-of-plane deformation vibration absorption peaks of 
$\mathrm{C}-\mathrm{H}$. Therefore, the AMDP was successfully fixed into the CA membrane by the immersion precipitation method and the composition structure of the probe was not changed.

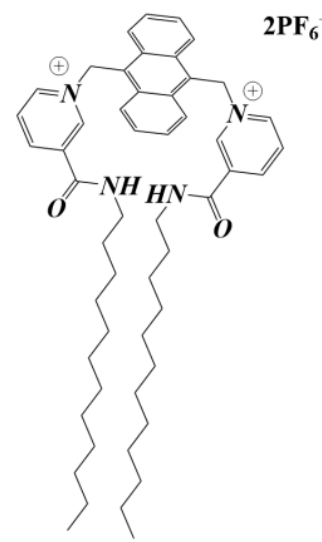

(a)

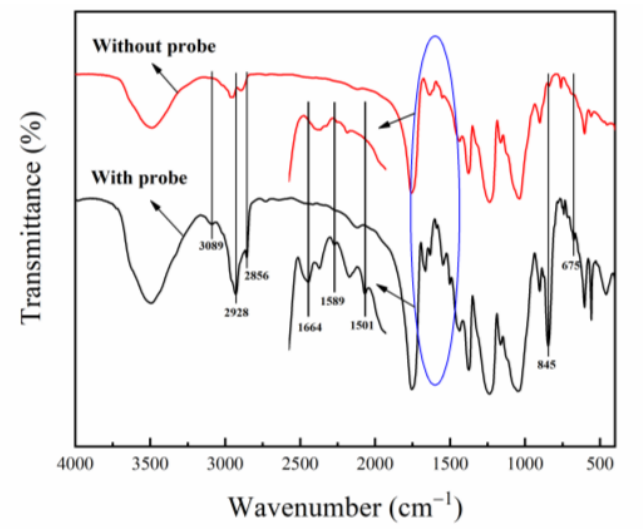

(b)

Figure 3. The structure of the fluorescent probe AMDP, (a) and the FT-IR contrast spectra of the CA membrane with and without the probe $(\mathbf{b})$.

\subsection{Properties of the Fluorescent Complex}

In order to verify that the probe AMDP can combine with sulfate ions to produce a fluorescent complex, we dropped the prepared the AMDP solution into a sodium sulfate solution, and obtained its excitation (EX) and emission (EM) spectra by fluorescence spectrometer. The EM spectrum of the mixed solution showed a separate fluorescence peak, which represented the successful generation and fluorescent emission of the $\mathrm{AMDP}-\mathrm{SO}_{4}{ }^{2-}$ complex. The UV-Vis absorption spectra of the AMDP- $\mathrm{SO}_{4}{ }^{2-}$ complex showed that there were several characteristic absorption peaks of anthracene group in the range from 300 to $400 \mathrm{~nm}$. Additionally, the peak values of the EX spectrum of the complex corresponded to the characteristic absorption peaks of anthracene group, which proved that the fluorescent cluster of the AMDP-SO ${ }_{4}{ }^{2-}$ complex is the anthracene group, as shown in Figure $4 \mathrm{a}, \mathrm{b}$. When the AMDP is bonded with sulfate ion via a hydrogen bond, the change of internal structure leads to the disappearance of the PET effect, which is also proved by the recovery of fluorescence of the anthracene group.

According to Equation (1), it is known that the increase of fluorescence lifetime is proportional to the increase of fluorescence intensity under ideal conditions, which indicates that the higher the fluorescence intensity is, the more significant the detection of fluorescence life will be. In order to improve the detection accuracy of fluorescence lifetime, the excitation wavelength of LED used in the sensor should be the optimal excitation wavelength of fluorescent complex. Figure $4 \mathrm{c}$ represents that the excitation wavelength of LED at $390 \mathrm{~nm}$ can achieve the best fluorescence lifetime detection effect.

In addition, the luminescence effect of the fluorescent complex was different under the different $\mathrm{pH}$ value environments. With the increase of $\mathrm{OH}^{-}$ion concentration, the ability of the AMDP probe to bind sulfate ions with hydrogen bonds is inhibited, leading to a rapid decline in the detection ability under the $\mathrm{pH}$ environment close to 13 . The cement starts facing corrosion issues when the $\mathrm{pH}$ value is higher than 10.5 [42], and the probe could work well in this environment, as shown in Figure 4d. 


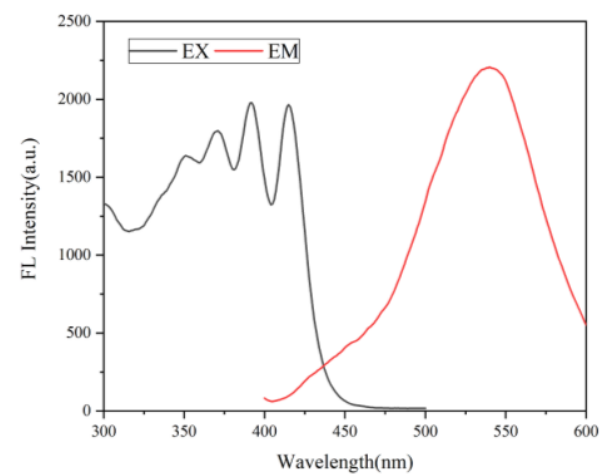

(a)

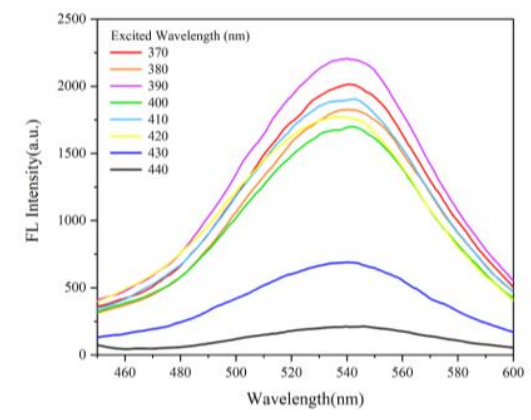

(c)

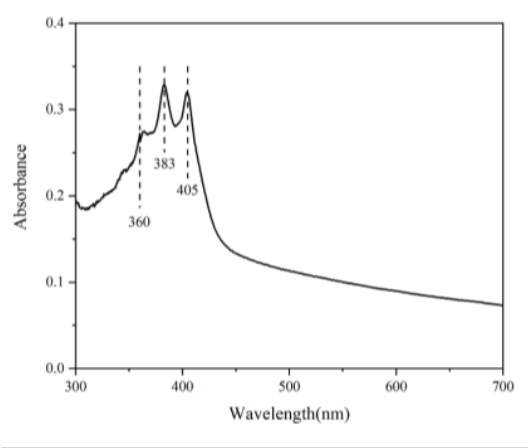

(b)

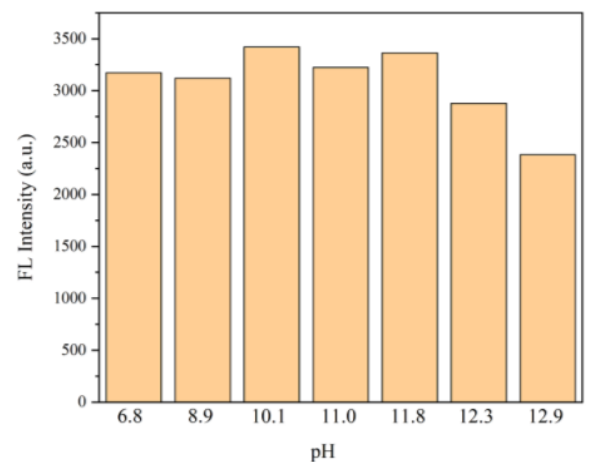

(d)

Figure 4. The fluorescence spectrum of the fluorescence intensity at $535 \mathrm{~nm}$ at different excitation wavelengths and the emission fluorescence spectrum at an excitation wavelength of $390 \mathrm{~nm}$ (a). Absorption spectrum of the $\mathrm{AMDP}_{-} \mathrm{SO}_{4}{ }^{2-}$ fluorescent complex (b). The fluorescence spectrum of the fluorescent complex at excited wavelengths from 370 to $440 \mathrm{~nm}$ (c) and the intensity of the fluorescent complex's fluorescence under different $\mathrm{pH}$ conditions (d).

\subsection{Response of the Fluorescent Probe when Detecting Sulfate Ions}

There are three stages in the formation of the fluorescent complex by the reaction of the probe AMDP with a sulfate ion. The first $15 \mathrm{~min}$ are the first stage of the reaction. The first step is the rapid reaction of the probe AMDP with sulfate radicals to form fluorescent complexes; the fluorescence intensity of solution increases rapidly as a consequence. With the eventual decrease in reaction rate, the fluorescence intensity of the solution stabilizes at a plateau stage. The fluorescence intensity of the complex is stable from 15 to $25 \mathrm{~min}$. When the reaction is completed, the fluorescence intensity of the fluorescent complex in the solution fluctuates for a period of time, and finally weakens to a very low fluorescence level. The fluorescence intensity of the complex at $25 \mathrm{~min}$ was used as the reference standard for measurement. The fluorescence intensity time curve of the fluorescent complex formed by the probe AMDP and sulfate ion is shown in Figure 5, and the dividing points of three stages are $15 \mathrm{~min}$ and $25 \mathrm{~min}$, respectively. 


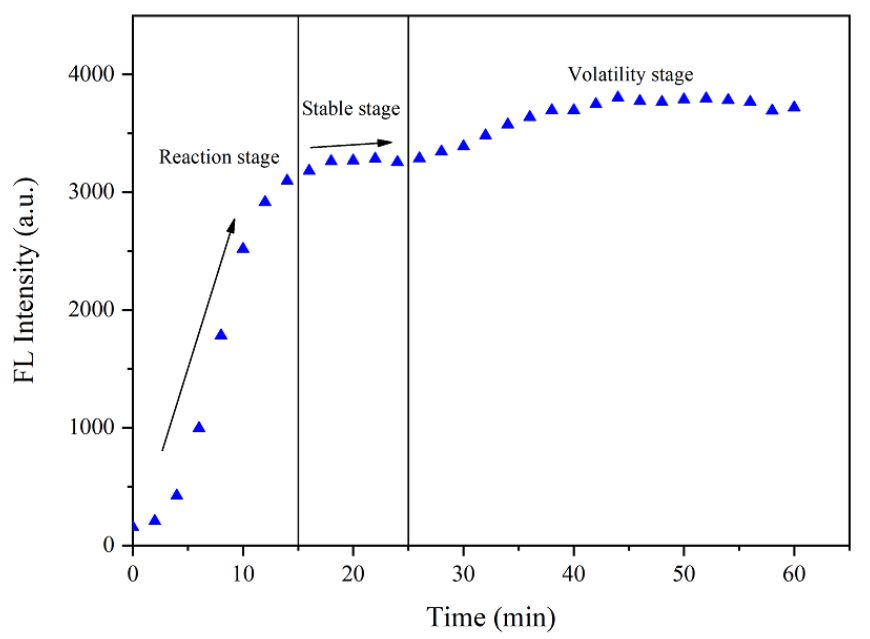

Figure 5. Time-intensity graph of the fluorescent complex.

\subsection{The Complexation Ratio and Fluorescence Lifetime of the Fluorescent Complex}

The complexation ratio of the fluorescent complex formed by the combination of sulfate ions and AMDP was researched by the Job plot method [43,44], as shown in Figure 6a. This result was confirmed by the Job plot method in which the fluorescence intensity exhibits a maximum at a molar fraction of approximately 0.5 , indicating that a 1:1 stoichiometry was the most likely binding mode for AMDP and $\mathrm{SO}_{4}{ }^{2-}$ ion. The 1:1 binding ratio of the fluorescent complex was also consistent with the binding pattern mentioned in the references [26]. Fluorescence lifetime is the essential parameter of matter producing a fluorescent signal. It refers to the time required for the fluorescence intensity of matter to decay to $1 / \mathrm{e}$ after being excited, which reflects the average stagnation time of an electron in an excited state. The fluorescence decay curve of the AMDP- $\mathrm{SO}_{4}{ }^{2-}$ fluorescent complex was measured by time-correlated single photon counting (TCSPC), as shown in Figure $6 \mathrm{~b}$. The decay of the fluorescence lifetime of the complex was in accordance with the double exponential fitting calculation. The fluorescence lifetimes were $23.22 \mathrm{~ns}$ and $165.97 \mathrm{~ns}$, and proportions of preexponential factors of both components were $27 \%$ and $73 \%$, respectively. The period of the excitation LED source $(40 \mathrm{kHz}), 25 \mu \mathrm{s}$, was much longer than the fluorescence lifetime of the fluorescent complex, which means that the phase difference caused by the change of fluorescence lifetime will not be particularly obvious.

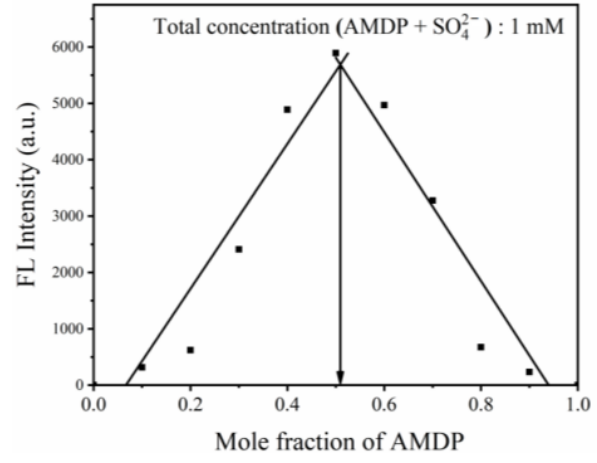

(a)

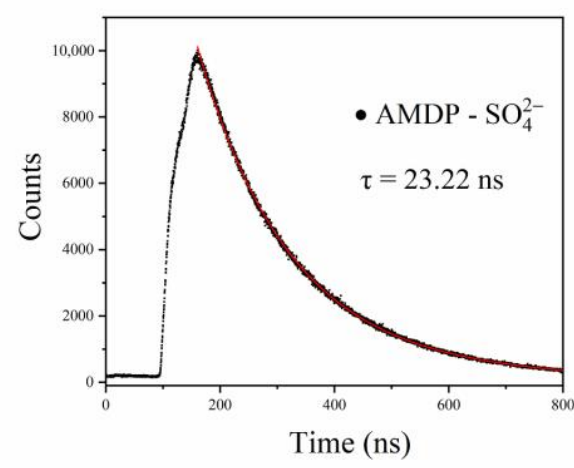

(b)

Figure 6. Fluorescence intensity diagram of the fluorescent complex with different ratios (a) and fluorescence decay curve of the fluorescent complex (b). 


\subsection{Reliability of the Sensitive Membrane}

As an essential parameter of the sulfate ion optical fiber sensor, the reliability of the sensitive CA membrane was demonstrated. As shown in Figure $7 \mathrm{a}$, the $10 \mathrm{mM}$ sulfate ion solution was tested by the sensor and the phase was stable after $25 \mathrm{~min}$, which showed that the fluorescent complex was successfully synthesized in the sensitive membrane and the stability was excellent. A leakage experiment was also carried out to ensure that AMDP would not leak during the monitoring process and contaminate the test solution. The absorption spectra of the $10 \mathrm{mM}$ sulfate solution into which the sensitive membrane was immersed from $2 \mathrm{~h}$ to $96 \mathrm{~h}$ were studied, as shown in Figure $7 \mathrm{~b}$. The characteristic absorption peaks of the fluorescent complex were not observed in the absorption spectra, which indicated that the immobilization of AMDP in the membrane was successful and that the fluorescent complex was stable during the measurement process.

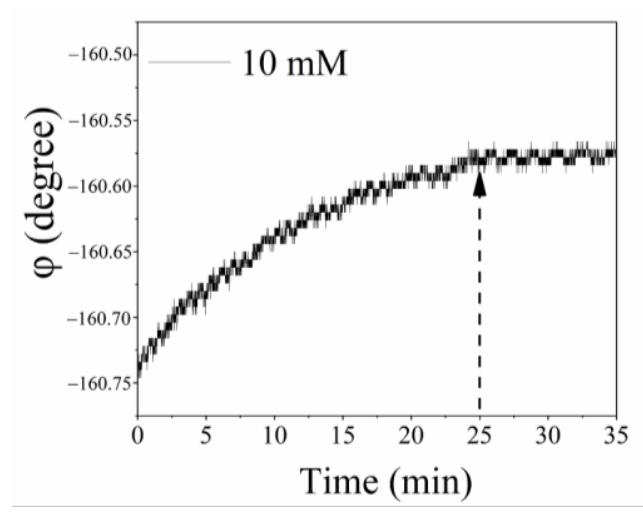

(a)

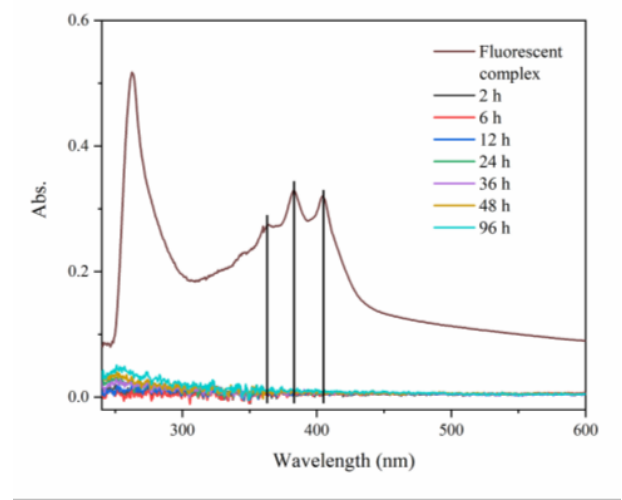

(b)

Figure 7. Time-phase diagram of sensitive CA membrane at detecting $10 \mathrm{mM}$ sulfate ion (a) and the absorption spectra of the fluorescent complex and the sensitive CA membrane immersed for 2, 6, 12, 24, 36, 48, and $96 \mathrm{~h}$ (b).

\subsection{Detection of Sulfate Ions with the Optical Fiber Sensor}

To improve the reliability of detection, it is necessary to replace the old sensitive membrane before using this sensor to detect the concentration of sulfate ions. When the optical fiber sensor detected the sulfate ions, the fluorescent phase shift $(\varphi)$ increased with the sulfate concentration, which was due to the different degree of fluorescence enhancement produced by the fluorescent probe AMDP and the sulfate concentration, as shown in Figure 8a. As the sulfate concentration increased from 2 to $10 \mathrm{mM}$, the fluorescence intensity and lifetime of the sensitive membrane also increased, and the sensor converted the fluorescence lifetime into a phase shift to obtain phase delay.

Due to the slight phase delay $(\Delta \varphi)$ of the sensitive membrane, $\tan \Delta \varphi$ could be converted into $\Delta \varphi$ during calculation. Therefore, the mechanism of sulfate detection was based on the fluorescence enhancement effect, which could be described by

$$
\Delta \varphi=\Delta \varphi_{0}+K[Q]
$$

where $K$ and $[Q]$ are the enhancement constant of the fluorescent complex and the concentration of $\mathrm{SO}_{4}{ }^{2-}$, respectively. In the formula, $\Delta \varphi_{0}$ means the phase delay caused by mechanical error. 

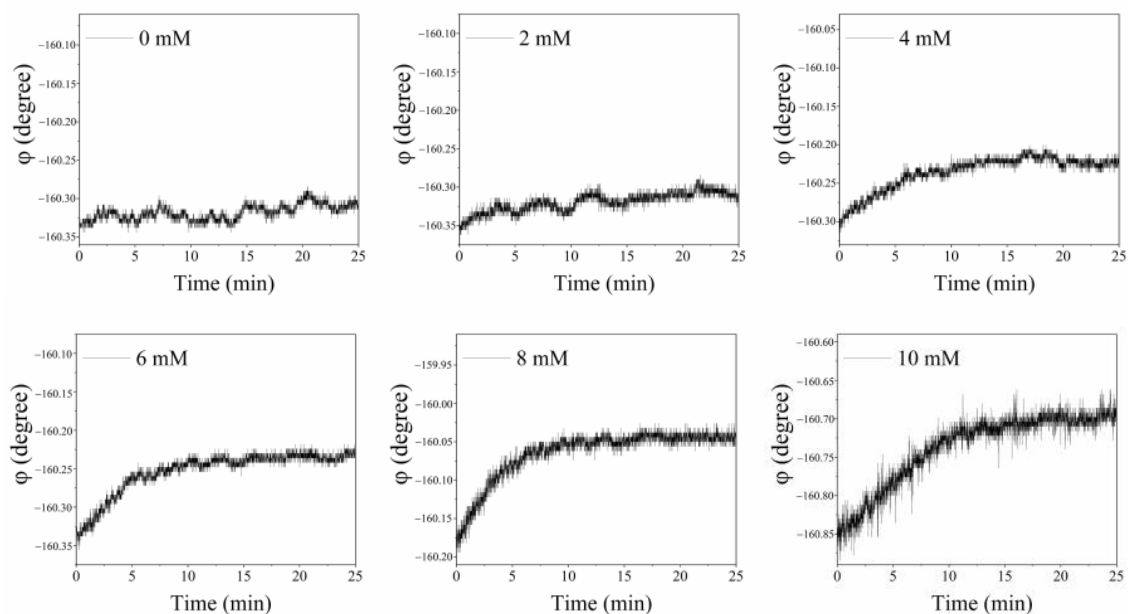

(a)

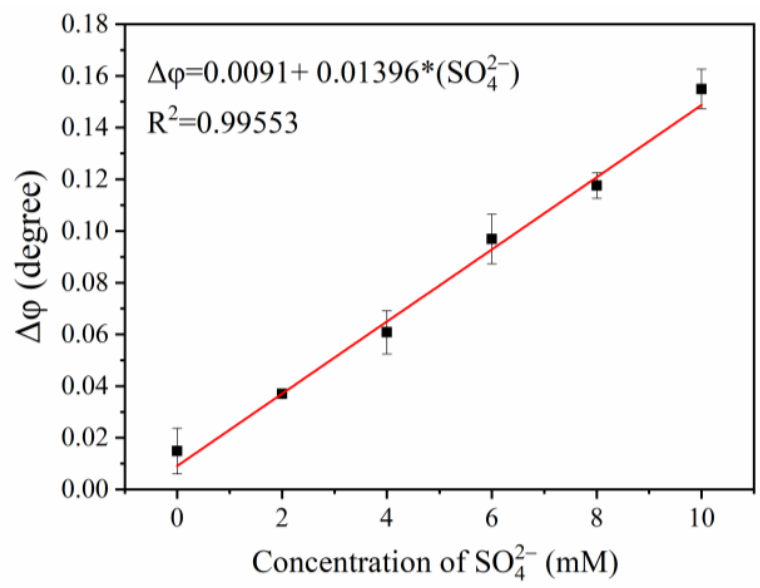

(b)

Figure 8. Time-phase diagram of the sensitive CA membrane at different sulfate ion concentrations (a) and the relationship between the phase delay $(\Delta \varphi)$ and the concentration of $\mathrm{SO}_{4}{ }^{2-}(\mathbf{b})$.

The average of the phase values was collected at the 1st minute and the 25th minute. The delay phase was obtained by the two average values, which could eliminate mechanical errors and obtain more accurate values. Each concentration of sulfate ions was measured by the sensor many times, and the corresponding standard deviation of phase difference value was obtained. The sensor has high detection stability, and the maximum variance and average variance were 0.00955 and 0.006657 , respectively. The calibration experiment of the sensor revealed the relationship between the sulfate concentration and the phase delay, as shown in Figure $8 \mathrm{~b}$. The relationship between the phase delay $(\Delta \varphi)$ and the sulfate concentration followed Equation (4), and a linear relationship equation $\Delta \varphi=0.0091+0.01396\left[S O_{4}^{2-}\right]\left(\mathrm{R}^{2}=0.99553\right)$ was obtained for a sulfate concentration range from 2 to $10 \mathrm{mM}$.

\subsection{Selective Experiment of the Optical Fiber Sensor}

According to a previous study [28], it is known that the structure of the fluorescent probe AMDP has a cavity suitable for forming hydrogen bonds with a sulfate ion, which means that it can specifically bind with a sulfate ion. We carried out selective detection of common anions $\left(\mathrm{HPO}_{4}{ }^{2-}, \mathrm{Br}^{-}, \mathrm{Cl}^{-}, \mathrm{CO}_{3}{ }^{2-}, \mathrm{I}^{-}, \mathrm{S}_{2} \mathrm{O}_{3}{ }^{2-}, \mathrm{SO}_{3}{ }^{2-}, \mathrm{NO}_{3}{ }^{-}, \mathrm{SO}_{4}{ }^{2-}\right)$ in a concrete environment. The concentration of chloride ions was $1 \mathrm{M}$ and other ions were $10 \mathrm{mM}$. The phase delay of the sensitive membrane $(\Delta \varphi)$ did not change significantly 
except for $\mathrm{SO}_{4}{ }^{2-}$ in the presence of each of the above chemical substances, which indicates that the optical fiber sensor has favorable selectivity for $\mathrm{SO}_{4}{ }^{2-}$ ions, as shown in Figure 9.

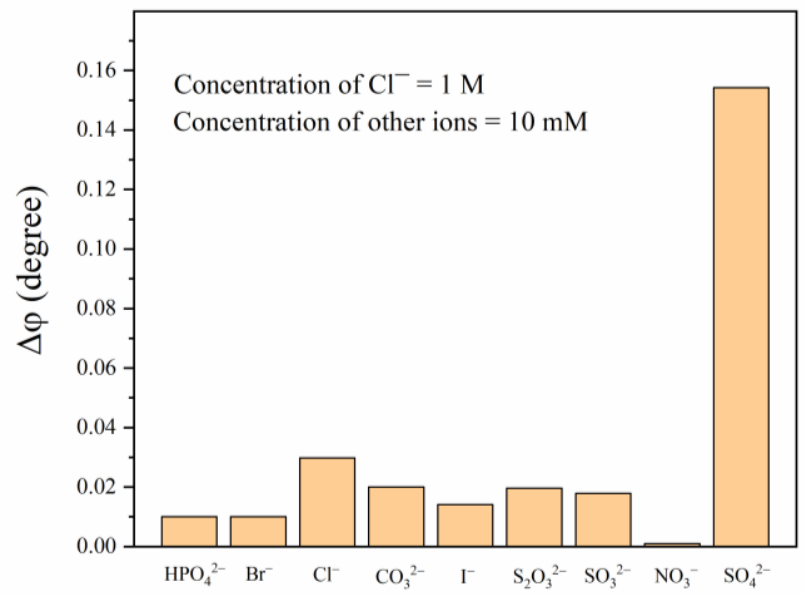

Figure 9. Effects of different ions on the phase delay $(\Delta \varphi)$ of the sensitive CA membrane.

In addition, some typical interference cations in concrete, such as $\mathrm{Ca}^{2+}$ and $\mathrm{Mg}^{2+}$, have little impact on sulfate detection of the sensor compared with $\mathrm{Na}^{+}$, as shown in Table 1 .

Table 1. Influences of different cations on the detection of $10 \mathrm{mM}$ sulfate ion by the sensor.

\begin{tabular}{ccc}
\hline Cations & $\Delta \varphi$ & Difference \\
\hline $\mathrm{Na}^{+}$ & 0.1543 & \\
$\mathrm{Ca}^{2+}$ & 0.1544 & +0.0001 \\
$\mathrm{Mg}^{2+}$ & 0.1493 & -0.005 \\
\hline
\end{tabular}

\section{Conclusions}

A new optical fiber sensor was prepared for detecting sulfate ion concentration based on the fluorescence lifetime, where AMDP contained in the sensitive membrane can specifically combine with a sulfate ion to form a stable fluorescent complex. The sensitive CA membrane with PEG 400 as the porogen has a porous structure on the surface and inside, which allows the sulfate ions in the solution to be fully combined with the fluorescent probe AMDP. The phase delay of fluorescence changed as the sulfate concentration increased from 2 to $10 \mathrm{mM}$, and the calibration equation of the sensor was $\Delta \varphi=0.0091+0.01396\left[\mathrm{SO}_{4}^{2-}\right]$ $\left(\mathrm{R}^{2}=0.99553\right.$, under DMSO- $\mathrm{H}_{2} \mathrm{O}$ (3:7) solution). This optical fiber sensor provided a promising method with repeatability, a short reaction time, and high selectivity. Moreover, the sensor has the potential for further research and development, and the hydrophilicity of the sensor can be improved by modifying the sensitive material to adapt to the detection environment.

Author Contributions: Conceptualization, P.G. and L.D.; methodology, P.G.; software, P.G. and B.X.; validation, P.G., L.D.; formal analysis, P.G.; investigation, P.G.; resources, P.G.; data curation, P.G.; writing - original draft preparation, P.G. and B.X.; writing-review and editing, P.G. and L.D.; visualization, Q.D.; supervision, L.D.; project administration, L.D. and Q.D.; funding acquisition, L.D. All authors have read and agreed to the published version of the manuscript.

Funding: This research has received funding from the Natural Science Foundation of China (number 51878524).

Institutional Review Board Statement: Not applicable.

Informed Consent Statement: Not applicable. 
Data Availability Statement: Data will be made available on request.

Acknowledgments: We give our thanks for the technology and equipment support from the Materials Research and Analysis Center of Wuhan University of Technology.

Conflicts of Interest: The authors declare no conflict of interest.

\section{References}

1. Zhang, J.R.; Sun, M.; Hou, D.S. External sulfate attack to reinforced concrete under drying-wetting cycles and loading condition: Numerical simulation and experimental validation by ultrasonic array method. Constr. Build. Mater. 2017, 139, 365-373. [CrossRef]

2. Clifton, J.R.; Pommersheim, J.M. Sulfate Attack of Cementitious Materials: Volumetric Relations and Expansions; National Institute of Standards and Technology: Gaithersburg, MD, USA, 1994; pp. 22-25.

3. Little, D.N.; Herbert, B.; Kunagalli, S.N. Ettringite Formation in Lime-Treated Soils. Transp. Res. Rec. J. Transp. Res. Board 2005, 1936, 51-59. [CrossRef]

4. Yazici, B.; Erbil, M. The effects of sulphate ion on concrete and reinforced concrete. Cem. Concr. Res. 1997, 27, 1271-1279.

5. Ma, B.G.; Gao, X.J.; Byars, E.A. Thaumasite formation in a tunnel of Bapanxia Dam in Western China. Cem. Concr. Res. 2006, 36, 716-722. [CrossRef]

6. Santhanam, M.; Cohen, M.D.; Olek, J. Sulfate attack research-Whither now? Cem. Concr. Res. 2001, 31, 845-851. [CrossRef]

7. Neville, A. The confused world of sulfate attack on concrete. Cem. Concr. Res. 2004, 34, 1275-1296. [CrossRef]

8. Zhang, M.; Liu, Y.Q.; Ye, B.C. Colorimetric assay for sulfate using positively-charged gold nanoparticles and its application for real-time monitoring of redox process. Analyst 2011, 136, 4558-4562. [CrossRef]

9. Tomita, K.; Ishioka, T.; Harata, A. Development of an anion probe: Detection of sulfate ion by two-photon fluorescence of gold nanoparticles. Anal. Sci. 2012, 28, 1139-1144. [CrossRef]

10. Du, Z.; Chen, J.; Ye, W.; Guo, J.; Zhang, X.; Zheng, R. Investigation of Two Novel Approaches for Detection of Sulfate Ion and Methane Dissolved in Sediment Pore Water Using Raman Spectroscopy. Sensors 2015, 15, 12377-12388. [CrossRef]

11. Chen, J.; Ye, W.; Guo, J.; Luo, Z.; Li, Y. Diurnal Variability in Chlorophyll-a, Carotenoids, CDOM and SO42- Intensity of Offshore Seawater Detected by an Underwater Fluorescence-Raman Spectral System. Sensors 2016, 16, 1082. [CrossRef]

12. Dedkov, Y.M.; Korsakova, N.V.; Sychkova, V.A. New metallochromic indicator for barium: Determination of sulfate in water and soil extracts. Am. J. Anal. Chem. 2006, 61, 1154-1162. [CrossRef]

13. Lutze, O.; Roß, B.; Cammann, K. Gran's plot titration and flow injection titration of sulfate in ground and drinking water with a barium ion-selective electrode. Fresenius' J. Anal. Chem. 1994, 350, 630-632. [CrossRef]

14. Chattaraj, S.; Das, A.K. Indirect atomic absorption spectrometric determination of sulfate in human blood serum. Analyst 1992, 117, 413. [CrossRef] [PubMed]

15. Liu, F.P.; Cheng, X.S.; Ge, J.P. Indirect determination of trace sulfate ion in sea water by graphite furnace atomic absorption spectrometry. Chin. J. Spectrosc. Lab. 2006, 23, 800-802.

16. Friedhelm, B.; Günther, S.; Karl-Heinz, J. A rapid and sensitive ion chromatographic technique for the determination of sulfate and sulfate reduction rates in freshwater lake sediments. FEMS Microbiol. Ecol. 1991, 85, 23-30.

17. Dick, W.A.; Tabatabai, M.A. Ion Chromatographic Determination of Sulfate and Nitrate in Soils. Soil Sci. Soc. Am. J. 1979, 43, 899. [CrossRef]

18. Chang, C.M.; Huang, H.J. Indirect determination of sulfate by atomic absorption spectrophotometry. J. Chin. Chem. Soc. 1993, 40, 425-428. [CrossRef]

19. Chimpalee, N.; Chimpalee, D.; Suparuknari, S.; Boonyanitchayakul, B.; Burns, D.T. Flow-injection spectrofluorimetric determination of sulphate using calcein and zirconium. Anal. Chim. Acta 1994, 298, 401-404. [CrossRef]

20. Colon, M.; Iglesias, M.; Hidalgo, M.; Todolí, J.L. Sulfide and sulfate determination in water samples by means of hydrogen sulfide generation-inductively coupled plasma-atomic emission spectrometry. J. Anal. At. Spectrom. 2008, 23, 416-418. [CrossRef]

21. Reisman, D.J.; Sundaram, V.; Al-Abed, S.R.; Allen, D. Statistical validation of sulfate quantification methods used for analysis of acid mine drainage. Talanta 2007, 71,303-311. [CrossRef]

22. Luo, J.; Yao, J.; Lu, Y. A Silver Nanoparticle-Modified Evanescent Field Optical Fiber Sensor for Methylene Blue Detection. Sensors 2013, 13, 3986-3997. [CrossRef] [PubMed]

23. Li, T.; Dai, Y.T.; Zhao, Q.C. A new type of high sensitivity optical fiber temperature sensor with microstructure. J. Optoelectron. Laser 2014, 25, 625-630.

24. Wang, W.; Yu, Q.; Jiang, X. High sensitivity diaphragm-based extrinsic Fabry-Perot interferometric optical fiber underwater ultrasonic sensor. Optoelectron. Adv. Mater. Rapid Commun. 2012, 6, 697-702.

25. Metje, N.; Chapman, D.N.; Rogers, C.D.F. An Optical Fiber Sensor System for Remote Displacement Monitoring of StructuresPrototype Tests in the Laboratory. Struct. Heal. Monit. 2008, 7, 51-63. [CrossRef]

26. Fouqué, B.; Schaack, B.; Obeïd, P.; Combe, S.; Getin, S.; Barritault, P.; Chaton, P.; Chatelain, F. Multiple wavelength fluorescence enhancement on glass substrates for biochip and cell analyses. Biosens. Bioelectron. 2005, 20, 2335-2340. [CrossRef]

27. Feng, X.; Duan, X.; Liu, L.; Feng, F.; Wang, S.; Li, Y.; Zhu, D. Fluorescence Logic-Signal-Based Multiplex Detection of Nucleases with the Assembly of a Cationic Conjugated Polymer and Branched DNA. Angew. Chem. 2009, 121, 5420-5425. [CrossRef] 
28. Saini, R.; Kumar, S. A fluorescent probe for the selective detection of sulfate ions in water. RSC Adv. 2013, 3, 21856. [CrossRef]

29. Houk, K.N. The Frontier Molecular Orbital Theory of Cycloaddition Reactions. Acc. Chem. Res. 1975, 8, 361-369. [CrossRef]

30. Tamayo, A.; Fernández-Lodeiro, J.; Escriche, L.; Casabó, J.; Covelo, B.; González, P.J. New fluorescence PET systems based on $\mathrm{N}_{2} \mathrm{~S}_{2}$ pyridine-anthracene-containing macrocyclic ligands. spectrophotometric, spectrofluorimetric, and metal ion binding studies. Inorg. Chem. 2005, 44, 8105-8115. [CrossRef]

31. De Silva, A.P.; Fox, D.B.; Moody, T.S.; Weir, S.M. The development of molecular fluorescent switches. Trends Biotechnol. 2001, 19, 29-34. [CrossRef]

32. Zhao, Y.; Zheng, H.K.; Li, G.L. Development of Fiber Optical Temperature Sensor Based on Fluorescence Lifetime; SPIE/COS Photonics Asia; Society of Photo-Optical Instrumentation Engineers (SPIE): Conference Series; SPIE: Beijing, China, 2016.

33. Wade, S.A.; Forsyth, D.I.; Grattan, K.T.V. Fiber optic sensor for dual measurement of temperature and strain using a combined fluorescence lifetime decay and fiber Bragg grating technique. Rev. Sci. Instrum. 2001, 72, 3186-3190. [CrossRef]

34. Lin, H.; Huang, J.; Ding, L. A recyclable optical fiber sensor based on fluorescent carbon dots for the determination of ferric ion concentrations. J. Light. Technol. 2019, 37, 4815-4822. [CrossRef]

35. Li, Z.; Ren, J.; Fane, A. Influence of solvent on the structure and performance of cellulose acetate membranes. J. Membr. Sci. 2006, 279, 601-607. [CrossRef]

36. Witte, P.V.D.; Dijkstra, P.J.; Berg, J.W.A.V.D. Phase separation processes in polymer solutions in relation to membrane formation. J. Membr. Sci. 1996, 117, 1-31. [CrossRef]

37. Idris, A.; Yet, L. The effect of different molecular weight PEG additives on cellulose acetate asymmetric dialysis membrane performance. J. Membr. Sci. 2006, 280, 920-927. [CrossRef]

38. Szmacinski, H.; Lakowicz, J.R. Optical measurements of $\mathrm{pH}$ using fluorescence lifetimes and phase-modulation fluorometry. Anal. Chem. 1993, 65, 1668-1674. [CrossRef]

39. Lakowicz, J.R. Topics in Fluorescence Spectroscopy: Probe Design and Chemical Sensing; Springer: Berlin/Heidelberg, Germany, 1994; Volume 4, pp. 295-334.

40. Ristein, J.; Stief, R.T.; Ley, L. A comparative analysis of a-C:H by infrared spectroscopy and mass selected thermal effusion. J. Appl. Phys. 1998, 84, 3836-3847. [CrossRef]

41. Torii, H.; Tasumi, M. Liquid Structure, Infrared and Isotropic/Anisotropic Raman Noncoincidence of the Amide I Band, and Low-Wavenumber Vibrational Spectra of Liquid Formamide: Molecular Dynamics and ab Initio Molecular Orbital Studies. Phys. Chem. B 1998, 102, 315-321. [CrossRef]

42. Fei, L.; Ruishu, W.; Ping, L.; Paul, R.O. Development of the metal oxides based fiber optic sensors for elevated temperature $\mathrm{pH}$ sensing applications (Conference Presentation). In Proceedings of the Chemical, Biological, Radiological, Nuclear, and Explosives (CBRNE) Sensing XXI, SPIE, Virtual, Online, USA, 27 April-8 May 2020; Available online: https: / / www.spiedigitallibrary.org/conference-proceedings-of-spie/11416/2558088/Metal-oxides-based-fiber-optic-pHsensors-for-elevated-temperature/10.1117/12.2558088.short?SSO=1\&tab=ArticleLin (accessed on 1 January 2021).

43. Maccarthy, P. Simplified experimental route for obtaining Job's curves. Anal. Chem. 2002, 50, 215. [CrossRef]

44. Park, J.; Rao, B.A.; Son, Y.A. "Turn-on" fluorescent and colorimetric determination of $\mathrm{Cu}^{2+}$ ions in aqueous media based on a Rhodamine-N-phenyl Semicarbazide derivative. Fibers Polym. 2015, 16, 953-960. [CrossRef] 